\title{
Uso da audiodescrição no brincar de uma criança com de Down na educação infantil
}

The use of audio description in the play of a child with down syndrome in kindergarten

Uso de la audiodescripción en el juego de un niño con síndrome de Down en la educación infantil

\section{* Tássia Lopes de Azevedo}

Doutora na Universidade Federal de São Carlos (UFSCar), São Carlos, São Paulo, Brasil.

tassia_to@hotmail.com

\section{** Gabriela Alias Rios}

Doutora na Universidade Estadual Paulista (UNESP), Presidente Prudente, São Paulo, Brasil. g.aliasrios@gmail.com

\section{*** Soellyn Elene Bataliotti}

Doutora na Universidade Estadual Paulista (UNESP), Presidente Prudente, São Paulo, Brasil. sol.bataliotti@gmail.com

\section{**** Gerusa Ferreira Lourenço}

Professora doutora na Universidade Federal de São Carlos (UFSCar), São Carlos, São Paulo, Brasil. gerusalourenco@gmail.com

Recebido: 25 de agosto de 2017

Aprovado: 8 de agosto de 2018

\section{RESUMO}

Este estudo trata do uso da audiodescrição (AD) como recurso para a inclusão escolar de uma criança com deficiência intelectual na educação infantil. A AD consiste em um recurso de tradução intersemiótica, do visual para o verbal. O objetivo desta pesquisa foi analisar o uso da $A D$ no brincar da criança com síndrome de Down. Participou desta pesquisa uma criança com Síndrome de Down matriculada em uma escola de educação infantil localizada no interior do estado de São Paulo. Foi realizado um programa de intervenção durante o período escolar que compreendeu cinco encontros semanais com duração de 60 minutos cada. Além disso, foram realizadas três sessões de observação de 90 minutos cada, sendo duas sessões antes e uma após a intervenção com a criança, de modo a comparar a influência que a intervenção teve sobre o aluno. Os resultados demonstraram que no caso de uma criança com deficiência intelectual, o recurso de audiodescrição pôde auxiliar de forma positiva na superação de barreiras e inclusão no âmbito escolar, pois se mostrou eficaz na estimulação da atenção e compreensão das brincadeiras. Conclui-se que é 
importante que algumas brincadeiras sejam adaptadas, utilizando recursos diferenciados, condizendo com a necessidade do aluno, de forma que este seja realmente incluído em todas as atividades lúdicas propostas pela professora.

Palavras-chave: Audiodescrição; Brincar; Educação infantil; Deficiência intelectual.

\section{ABSTRACT}

This study deals with the use of audio description (AD) as a resource for the inclusion of a child with Down Syndrome in early childhood education. AD consists of a intersemiotic translation resource, from visual signs to verbal ones. Thus, this research aimed to analyze the use of $A D$ in the play of children with Down syndrome. A child with Down syndrome enrolled in a kindergarten school located in the state of São Paulo participated of this study. An intervention program was conducted with the child during the school period. The intervention occurred in five weekly meetings lasting 60 minutes each. In addition, there were three 90-minute observation sessions each, two sessions before and after the intervention with the child. The observations were performed to compare the influence that the intervention had on the student. The results showed that in the case of a child with intellectual disabilities, the use of $A D$ could assist positively in overcoming barriers and inclusion in schools, as proved very effective in stimulating attention and understanding of the play. It was concludes that it is important to adapt some plays by using different resources, according to the need of the student, in order to really include in all activities proposed by the teacher.

Keywords: Audio description; Play; Childhood education; Intellectual disability.

\section{RESUMEN}

Este estudio trata del uso de la audiodescripción (AD) como recurso para la inclusión escolar de un niño con discapacidad intelectual en la educación infantil. La AD consiste en un recurso de traducción intersemiótica, de lo visual a lo verbal. El objetivo de esta investigación fue analizar el uso de la $A D$ en el juego del niño con síndrome de Down. Participó de esta investigación un niño con Síndrome de Down matriculado en una escuela de educación infantil localizada en el interior del estado de São Paulo. Se realizó un programa de intervención durante el período escolar que comprendió cinco encuentros semanales con una duración de 60 minutos cada uno. Además, se realizaron tres sesiones de observación de 90 minutos cada una, siendo dos sesiones antes y una después de la intervención con el niño, para comparar la influencia que la intervención tuvo sobre el alumno. Los resultados demostraron que en el caso de un niño con discapacidad intelectual, el recurso de audiodescripción pudo ayudar de forma positiva en la superación de barreras e inclusión en el ámbito escolar, pues se mostró eficaz en la estimulación de la atención y comprensión de los juegos. Se concluye que es importante que bromas sean adaptadas, 
utilizando recursos diferenciados, condicionando con la necesidad del alumno, de forma que éste sea realmente incluido em las actividades lúdicas propuestas por la profesora.

Palabras clave: Descripción de audio; Educación Infantil; Discapacidad intelectual.

\section{Introdução}

A política de educação inclusiva objetiva oportunizar a educação para todos de forma democrática, gerando direções e ampliações ao acesso para o ensino público de qualidade e a garantia do direito à cidadania. Crianças com deficiência têm direito à escolarização na rede regular de ensino e necessitam de oportunidades de aprendizagem que estimulem seu potencial cognitivo, afetivo e social. Assim, para o que está previsto na política inclusiva seja levado ao cotidiano escolar, torna-se necessário que a escola seja modificada para receber o aluno com deficiência (OLIVEIRA, 2007).

O processo inclusivo demanda a adaptação de recursos e estratégias para promover o processo de ensino-aprendizagem e diante disso é fundamental levar em consideração que brinquedos e brincadeiras também precisam ser adaptados para as crianças com deficiência, principalmente na educação infantil, cujo foco é o desenvolvimento humano e social da criança. Para crianças na primeira e segunda infância, o brincar e o brinquedo constituem importantes recursos para pais e educadores promoverem a aprendizagem infantil. A inclusão escolar deve iniciar o mais precoce possível, pois é na infância que as bases necessárias para a construção do conhecimento e seu desenvolvimento global são desenvolvidas (MENDES, 2010).

Do nascimento aos três anos de idade, o atendimento educacional especializado (AEE) complementar ao ensino comum conforme previsto pela Política atual (BRASIL, 2008) é oferecido por meio dos programas de intervenção precoce, que objetivam otimizar o processo de desenvolvimento e aprendizagem em interface aos serviços de saúde e assistência social. Prevê-se que a criança receba o AEE na própria escola regular, onde está incluída, ou em centros especializados.

O brincar tem inúmeros potenciais na perspectiva inclusiva, pois a atividade lúdica permite a interação e convivência de crianças com deficiência com seus pares em um mesmo espaço, além de propiciar diversos fazeres e experimentações ricas para o desenvolvimento infantil. Para Piaget (1978), a origem das manifestações lúdicas 
acompanha o desenvolvimento da inteligência vinculando-se aos estágios do desenvolvimento cognitivo.

$\mathrm{Na}$ infância, o brincar é uma necessidade básica, e as atividades lúdicas auxiliam a criança no seu desenvolvimento global, pois através das brincadeiras a criança forma conceitos, relaciona ideias, estabelece relações lógicas, desenvolve a expressão oral e corporal, reforça habilidades sociais, reduz a agressividade, integra-se na sociedade e constrói seu próprio conhecimento (FERREIRA, 2007).

A brincadeira não depende de formas rígidas e estruturadas, é um ato de espontaneidade e de imaginação. Além de promoverem às crianças a liberação de energias, estimulam o desenvolvimento da criatividade e sociabilidade (GARCIA; MARQUES, 1990).

De acordo com Vygotsky (1994), além de proporcionarem prazer, as brincadeiras também suprem as necessidades da criança para avançarem em seu desenvolvimento. Sendo assim, as brincadeiras não são apenas atividades de entretenimento para gastar energia, mas são meios que contribuem e enriquecem o desenvolvimento cognitivo (PIAGET, 1976). Nesse sentido, o ambiente escolar se torna um dos espaços mais importantes de resgate e de incentivo à cultura lúdica infantil.

O brincar se estende aos vários campos da atividade humana, inclusive na educação. As brincadeiras são atividades naturais da criança que se constituem em um espaço que envolve o aprendizado e o desenvolvimento infantil. Deste modo, é importante que as brincadeiras sejam ofertadas de acordo com a idade e o estágio da criança (ALVES; SOMMERHALDER, 2006).

As brincadeiras vivenciadas na escola criam condições para a criança avançar no seu desenvolvimento cognitivo, porém, é importante que os professores considerem que o sistema simbólico e imaginário de cada aluno é único, sem generalizar as situações (MAGALHÃES, 2008). As brincadeiras devem aguçar a curiosidade dos alunos, e cabe ao professor orientá-los na descoberta das possibilidades oferecidas pelo brincar, respeitando o momento de aprendizagem e individualidade de cada criança (CÓRIA-SABINI; LUCENA, 2004), pensando e questionando sobre sua forma de ensinar, relacionando a utilização do lúdico como fator estimulante e o brincar como um facilitador para a aprendizagem (ROCHA, 2000). 
A criança com deficiência necessita de recursos para ser efetivamente incluída nas brincadeiras e atividades que fazem parte da rotina da educação infantil. A audiodescrição é um recurso pedagógico simples, sem custo e que permite ao professor incluir alunos com deficiências nas atividades. Com a utilização da audiodescrição $(A D)$ as imagens do livro didático, ou de filmes, geralmente cheias de detalhes e coloridas e frequentemente utilizadas na educação infantil, tornam-se acessíveis a todos os alunos.

A $A D$ consiste em uma atividade de mediação linguística, uma modalidade de tradução intersemiótica, em que o visual é traduzido para o verbal. Configura-se em um recurso de acessibilidade e Tecnologia Assistiva, que favorece positivamente o entendimento de pessoas com deficiência visual, idosos, disléxicos e também, pessoas com deficiência intelectual (MOTTA; ROMEU FILHO, 2010). A audiodescrição viabiliza que elementos significativos e importantes do conteúdo imagético sejam transformados em palavras, o que permite às pessoas com deficiência visual (e a outros públicos que podem se utilizar dessa técnica) a equiparação de oportunidades no que diz respeito à compreensão de cenas, imagens, efeitos visuais e espaços.

A Lei n 10.098/2000 (BRASIL, 2000) estabelece as normas gerais para promoção da acessibilidade de pessoas com deficiência ou mobilidade reduzida. A acessibilidade é definida como a possibilidade e condição de alcance aos espaços, transportes e comunicação, pela pessoa com deficiência.

Quanto à comunicação, a lei define como barreira qualquer entrave que prejudique o recebimento ou a expressão de mensagens, por meio de sistemas de comunicação, que podem ou não ser de massa. Também prevê que barreiras na comunicação sejam eliminadas e técnicas e mecanismos sejam adotados para garantir a essas pessoas 0 direito de acesso à informação, comunicação, trabalho, educação, transporte, cultura e lazer.

Nesse sentido, o professor pode o professor pode utilizar da audiodescrição de maneira mais informal, adicionando a audiodescrição à sua fala, audiodescrevendo gestos, expressões faciais, brincadeiras que ocorrem nos diversos ambientes em que a criança está inserida, bem como os diversos espaços da escola.

Além disso, a AD pode ser reconhecida como um recurso de Tecnologia Assistiva, que prevê recursos, estratégias e serviços em prol da melhoria na funcionalidade de 
pessoas com deficiência na realização de atividades rotineiras, propiciando participação e inclusão social. Nos espaços de AEE e também no ensino comum o uso de recursos e estratégias de tecnologia assistiva é previsto de modo a promover a participação de todas as crianças (com deficiência ou não) nas atividades realizadas, inclusive sendo de responsabilidade do professor do AEE a sua implementação.

Diante da importância do brincar como recurso pedagógico, o objetivo desta pesquisa foi o de analisar a influência do uso da audiodescrição no brincar de uma criança com síndrome de Down matriculada na educação infantil.

\section{Metodologia}

Foi proposto um delineamento ABA, com pré e pós teste (COZBY, 2006), de modo a medir os impactos do programa de intervenção do uso da audiodescrição no brincar infantil.

Participou desta pesquisa uma criança com deficiência intelectual de dois anos e oito meses de idade, matriculada em uma escola de ensino infantil da rede privada, localizada em um município no interior de São Paulo. Foi utilizado como critério a criança ser diagnosticada com deficiência intelectual, mais especificamente síndrome de Down, e frequentar a pré-escola por no mínimo seis meses.

Para a coleta de dados, utilizou-se um instrumento, que consiste em uma tabela de registro de observação. Este instrumento foi elaborado para a observação da criança antes e após a intervenção e é composto por duas partes principais - uma com informações de identificação do participante (mantida em sigilo) e diagnóstico. A segunda parte é destinada para a observação, e composta por quatro categorias que contemplam o desenvolvimento da criança - habilidades funcionais, sociais, linguísticas, desenvolvimento cognitivo. As habilidades funcionais são relacionadas à destreza da criança na realização de atividades motoras, cognitivas e interacionais; as sociais são as ações da criança diante dos colegas de classe, em atividades educativas que envolvem o brincar e demais tarefas, como a música, contação de história etc.; a habilidade linguística envolve a comunicação da criança com a professora, com a comunidade escolar e com os colegas de classe; em relação ao desenvolvimento cognitivo, considera-se o comportamento motor e sensorial infantil diante das atividades pedagógica de acordo com a idade da criança. 
Cada categoria é constituída de um conjunto de ações observáveis, que devem ser respondidas entre "sim" e "não". Cada uma das ações recebe uma pontuação, sendo atribuído o valor 2 (dois) para as ações que consegue fazer, e 0 (zero) para as ações que não realiza.

O questionário passou por avaliação de três juízes, para validação e utilização na intervenção.

Antes de iniciar a pesquisa foram utilizados, também, procedimentos observacionais do cotidiano educacional da criança, principalmente na utilização de procedimentos lúdicos nas atividades pedagógicas. Nesta fase, foi utilizada a tabela de observação, atribuindo-se o valor a cada ação nas categorias. A partir dos dados coletados na observação, foi desenvolvido um plano de intervenção que teve como foco o uso da audiodescrição no brincar infantil.

\section{Coleta de dados}

Procedimentos preliminares: a instituição escolar e os responsáveis pelo aluno consentiram com a realização do estudo.

A coleta de dados seguiu o mesmo procedimento no pré-teste e no pós-teste. O préteste foi realizado antes da intervenção e o pós-teste ocorreu após o término da intervenção, ou seja, decorridos aproximadamente um mês e vinte dias da coleta de préteste. Foram realizadas quatro sessões de observação de uma hora e meia cada, sendo duas sessões antes e duas após a intervenção com a criança. As observações foram realizadas para comparar o impacto que a intervenção teve sobre o aluno.

\section{Intervenção}

A intervenção foi realizada em cinco encontros semanais de 60 minutos cada. Os encontros ocorreram no período de aula da criança, respeitando o planejamento da professora da sala. A partir da atividade proposta pela professora, as pesquisadoras desenvolviam a intervenção. Não eram elaboradas atividades diferenciadas, ou que exigissem que o participante fosse retirado da sala de aula, ou que atrapalhasse sua interação com os demais colegas da sala. As pesquisadoras tiveram acesso ao plano de 
aula previamente, obtendo conhecimento do que seria trabalhado enquanto estivessem na sala de aula para realizar a intervenção.

Considerando que o participante está frequentando a pré-escola e que a maioria das atividades realizadas nesta faixa etária é desenvolvida de forma lúdica por meio do brincar, nas sessões com a criança, a AD foi usada durante os momentos em que era necessária alguma explicação e imagens eram apresentadas à criança, como na contação de história, ou em atividades em que se trabalhava com música e eram usados cartões para apresentar às crianças algum vocábulo importante para o desenvolvimento da atividade. Nas atividades que envolviam música, foi utilizada a AD para descrever o cartão com as figuras relacionadas à música (animais, partes do corpo e expressões faciais). Nas atividades que envolviam o desenvolvimento motor e noção espacial, a AD foi utilizada para descrever o cenário da atividade e os objetos utilizados, como cores, formas e maneiras de encaixe.

Durante a contação de história, a professora da sala contou uma história apresentada pelo material didático adotado pela instituição escolar, com o auxílio do livro, figuras grandes e fantoches. Foi feita a audiodescrição das imagens do livro e também do fantoche utilizado durante a atividade.

O Quadro 1 ilustra como foram realizados os encontros, com relação às atividades propostas, objetivos e realização das intervenções.

Quadro 1 - Realização dos encontros, atividades, objetivos e intervenções

\begin{tabular}{|l|l|l|l|}
\hline Encontro & Atividade & \multicolumn{1}{|c|}{ Objetivo } & \multicolumn{1}{c|}{ Intervenção } \\
\hline 1 & $\begin{array}{l}\text { Música - "O } \\
\text { sapo não } \\
\text { lava o pé" }\end{array}$ & $\begin{array}{l}\text { Noção corporal e espacial - } \\
\text { reconhecimento de partes do } \\
\text { corpo - pé, e lateralidade }\end{array}$ & $\begin{array}{l}\text { As pesquisadoras utilizaram a } \\
\text { audiodescrição informal para descrever o } \\
\text { cartão com a figura de um sapo. } \\
\text { Também foi explicado o significado da } \\
\text { palavra pé, mostrando no próprio corpo da } \\
\text { criança, para que ela internalizasse o } \\
\text { significado da palavra pé. Quanto a } \\
\text { lateralidade, as pesquisadoras sinalizaram } \\
\text { de forma verbal o momento que a criança } \\
\text { teria que movimentar os membros } \\
\text { superiores (braços e mãos) ou inferiores } \\
\text { (pernas e pés) para frente, trás, laterais, } \\
\text { em baixo e em cima. Isso ocorria quando a } \\
\text { criança se perdia ou dispersava na } \\
\text { atividade. }\end{array}$ \\
\hline 2 & $\begin{array}{l}\text { Atividade } \\
\text { motora }\end{array}$ & $\begin{array}{l}\text { Atividade elaborada pela } \\
\text { professora para trabalhar a }\end{array}$ & $\begin{array}{l}\text { Uso da audiodescrição para descrever o } \\
\text { caminho e explicar a atividade. A criança }\end{array}$ \\
\hline
\end{tabular}




\begin{tabular}{|c|c|c|c|}
\hline & & $\begin{array}{l}\text { motricidade grossa, } \\
\text { coordenação global e noção } \\
\text { espacial. As crianças deveriam } \\
\text { passar entre um caminho feito } \\
\text { por duas fitas, e também sobre } \\
\text { as fitas. }\end{array}$ & $\begin{array}{l}\text { foi acompanhada pelo caminho com uma } \\
\text { das pesquisadoras. }\end{array}$ \\
\hline 3 & $\begin{array}{l}\text { Contação } \\
\text { de história }\end{array}$ & $\begin{array}{l}\text { A professora da sala contou } \\
\text { uma história apresentada pelo } \\
\text { material didático adotado pela } \\
\text { instituição escolar. A história foi } \\
\text { contada com utilização do livro, } \\
\text { com figuras grandes e } \\
\text { fantoches. }\end{array}$ & $\begin{array}{l}\text { As imagens foram explicadas à criança por } \\
\text { meio da audiodescrição do livro. Após } \\
\text { contar a história, a professora } \\
\text { disponibilizou o fantoche para que as } \\
\text { crianças pudessem manipular. A AD foi } \\
\text { usada também para descrever o fantoche. }\end{array}$ \\
\hline 4 & $\begin{array}{l}\text { Brinquedo - } \\
\text { Jogo de } \\
\text { encaixar }\end{array}$ & $\begin{array}{l}\text { Trabalhar motricidade grossa e } \\
\text { fina; quantificação; cores; } \\
\text { diferenciação de formas e } \\
\text { tamanhos; exploração de } \\
\text { objetos }\end{array}$ & $\begin{array}{l}\text { Uso da audiodescrição para descrever os } \\
\text { objetos, suas cores e formas. As } \\
\text { pesquisadoras descreveram as peças e } \\
\text { mostraram, dando modelos, como era o } \\
\text { encaixe de cada jogo, para que a criança } \\
\text { pudesse fazer sozinha. }\end{array}$ \\
\hline 5 & $\begin{array}{l}\text { Música - "A } \\
\text { barata diz } \\
\text { que tem" }\end{array}$ & $\begin{array}{l}\text { números-quantificação; } \\
\text { expressão corporal (gestos) e } \\
\text { facial; }\end{array}$ & $\begin{array}{l}\text { Uso da audiodescrição para explicação } \\
\text { dos principais elementos da música. } \\
\text { Execução de movimentos durante a } \\
\text { música - as pesquisadoras realizavam } \\
\text { como modelo mostrando os gestos e } \\
\text { expressões faciais, para que a criança } \\
\text { pudesse imitar e acompanhar a coreografia } \\
\text { da música sozinha. }\end{array}$ \\
\hline
\end{tabular}

Fonte: Elaborado pelas autoras

\section{Procedimento de análise de dados}

Os dados obtidos a partir da tabela foram quantificados a fim de avaliar a influência da intervenção no desenvolvimento da criança. A pontuação obtida na fase de observação foi comparada com a pontuação obtida após a realização da intervenção.

\section{Resultado e Discussão}

Os resultados foram obtidos a partir da comparação da aplicação do instrumento antes e após a intervenção. Cada uma das categorias (habilidades funcionais, sociais, linguísticas, desenvolvimento cognitivo) foi analisada separadamente, e o total de pontos obtidos em cada categoria, somados.

Figura 1 - Impacto da intervenção na aprendizagem da criança 


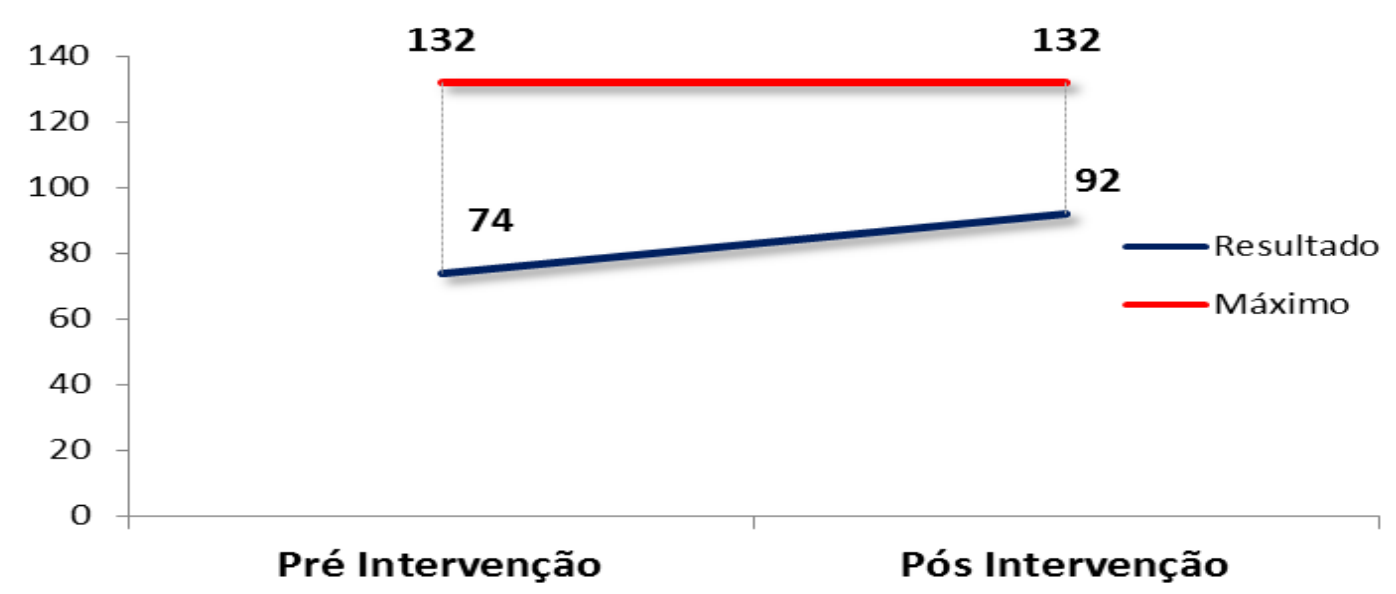

Como mostra o Gráfico 1, a intervenção influenciou positivamente no desenvolvimento da criança, de modo geral, pois obteve 92 pontos na observação após a intervenção, dezoito a mais que no período anterior à intervenção.

Após a intervenção, observou-se que a criança interagia mais com os colegas de sala, nas brincadeiras de grupo, e também começou a responder positivamente a comandos simples, como pegar a lancheira, ir para a fila, e dirigir-se ao refeitório. De acordo com Motta (2010), a audiodescrição é um recurso de modalidade de tradução intersemiótica que favorece positivamente na compreensão da criança com deficiência intelectual, possibilitando o acesso ao universo imagético da sala de aula, permitindo que preste atenção na imagem, observando os detalhes.

Porém, a dificuldade da criança em comunicar-se verbalmente e gestualmente com a professora e colegas, e de participar de brincadeiras de faz-de-conta, é decorrente de uma dificuldade na fala. Grande parte de crianças com síndrome de Down apresentam déficits na aquisição e desenvolvimento da fala, que podem ser atribuídos as características físicas e ambientais que influenciam negativamente no processo de desenvolvimento (BARATA; BRANCO, 2010).

Desenvolver somente habilidades motoras orais pode não ser suficiente para que as crianças adquiram fala e linguagem. As crianças com síndrome de Down devem compreender que os sons são instrumentos utilizados na comunicação e estes serão os grandes elementos de motivação para que elas empreguem seus esforços com o intuito de aprender a articular os sons da fala (BARATA; BRANCO, 2010; WERNECK, C., 1993). Sendo assim, as trocas comunicativas ofertadas por meio da $A D$ podem propiciar a 
compreensão da linguagem pela criança, a atribuição de significado às suas emissões e a aprendizagem e o desenvolvimento cognitivo.

Constata-se que a criança entende comandos simples e o que the é falado, mostrando-se curiosa ao que acontece na sala de aula e com novos objetos. Porém, a mesma não reconhecia as partes do corpo, o que passou a fazer após a intervenção. No ambiente escolar, é importante que o professor utilize a AD nos diversos momentos da aula, já que possibilita que a criança tenha acesso ao universo imagético da sala de aula.

Em uma das sessões, foi utilizado o recurso de audiodescrição para trabalhar uma atividade de música com algumas partes do corpo. A utilização da audiodescrição para explicação contribuiu para que a criança aprendesse a palavra " pé'. Durante a contação de história, o mesmo método foi utilizado para apresentação do fantoche que representava o contador da história. Foram trabalhadas as partes do rosto nesta atividade. A AD possibilita que crianças com deficiência intelectual tenham conhecimento das ilustrações do livro, além de permite que prestem atenção na imagem, observando os detalhes. Assim, a audiodescrição pode ser classificada como um recurso de Tecnologia Assistiva, que propicia a inclusão, nos mais diversos contextos, como atividades voltadas para a cultura e lazer, e também, escolares.

Ao aplicar o pós-teste, observou-se que a criança passou a manipular melhor sólidos geométricos e brinquedos construtivos (jogos de encaixe), sendo capaz de encaixar peças e construir torres. Também houve mudança no que se refere à atenção da criança. Como esclarecem Motta e Romeu Filho (2010), a AD contribui para a ampliação do entendimento de pessoas com deficiência intelectual, já que trabalha com um segundo canal sensorial a audição. Dessa forma, influencia no desenvolvimento do poder de observação e a fluência verbal, ampliando o léxico e a cultura, de forma geral.

Algumas ações como responder a comandos complexos, localizar e reconhecer figuras quando nomeadas, organizar quebra-cabeças e realizar ações que dependiam da fala não apresentaram mudança após o período de intervenção. Tal fato pode ter ocorrido devido ao pequeno número de intervenções aplicadas com a criança, o que possibilitou atingir resultados a curto e médio prazo com a criança, sendo necessário maior número de intercessões para atingir objetivos mais complexos. O recurso da AD permite ao professor tornar sua aula acessível ao aluno com deficiência intelectual, porém deve ser aplicada de 
forma contínua, permitindo que o aluno preste atenção nos detalhes, imagens e movimentos das atividades pedagógicas e lúdicas ofertadas na pré-escola.

Assim, no contexto escolar, faz-se necessário que barreiras comunicacionais sejam quebradas, viabilizando o acesso ao conteúdo por todos os alunos. Tornar o ambiente escolar acessível, bem como todos os conteúdos trabalhados, é fundamental para que ocorra a inclusão.

\section{Considerações Finais}

Este artigo mostra que a brincadeira é uma boa maneira de estimular o desenvolvimento físico, cognitivo, linguístico e social da criança. Porém, conclui-se que para crianças com deficiência, algumas brincadeiras devem ser adaptadas às necessidades que apresentam, utilizando recursos diferenciados que condizem com a necessidade do aluno, de forma que este seja incluído em todas as atividades lúdicas propostas pela professora. O brincar não deve acontecer de forma rígida e estruturada, mas estimular a espontaneidade e a imaginação.

O brincar é uma atividade indispensável como aprendizagem às crianças com deficiência, pois estimula a exploração e a construção do conhecimento. É na infância que as crianças, por meio das brincadeiras, satisfazem grande parte de seus desejos e interesses particulares (GARCIA; MARQUES, 1990). Diante disso, a diversidade de recursos é fundamental para que as crianças tenham a oportunidade de liberar energias, desenvolver a criatividade e a sociabilidade.

Sendo assim, constatou-se que, no caso de uma criança com Síndrome de Down, a audiodescrição pode auxiliar de forma positiva na superação de barreiras e inclusão no âmbito escolar, pois se mostrou muito eficaz na estimulação da atenção e compreensão das brincadeiras. Além disso, ao demonstrar maior compreensão da brincadeira, a criança com deficiência passa a sentir mais interesse em participar das atividades lúdicas, podendo ser um incentivo para que esta interaja com os outros colegas de sala. Dessa forma, a audiodescrição também demonstrou ser um recurso que estimula a socialização infantil de alunos com deficiência.

Quanto à intervenção realizada, o que pôde ser observado é a necessidade de um atendimento individualizado desse aluno com deficiência, como um suporte para as 
atividades realizadas em sala de aula. A partir do estudo realizado, foi possível notar que mesmo a escola seguindo os princípios e paradigmas da escola inclusiva, em que a criança participava de todas as brincadeiras e atividades planejadas pela professora, o atendimento individualizado se fez necessário para atender às necessidades dessa criança. Assim, prever esse atendimento individualizado pode ser um ponto positivo e benéfico ao desenvolvimento da criança público-alvo da educação especial matriculada na educação infantil.

Outro ponto relevante é que este estudo apresenta limitações. Esta investigação foi realizada em um curto espaço de tempo. Nesse sentido, este estudo poderia ser ampliado observando outros aspectos da inclusão da criança com deficiência intelectual na educação infantil, por um período maior de tempo. Além disso, a utilização da audiodescrição em mais atividades também poderiam ser observadas, tanto com os estudantes público-alvo da educação especial, quanto com os que não são.

Ademais, algumas técnicas audiodescritivas poderiam ser passadas para a professora da sala, que poderia acrescentar essas informações descritivas já em sua fala, como a descrição das personagens das histórias contadas, das ilustrações dos livros utilizados nas atividades de contação de histórias, por exemplo.

Nesse sentido, tanto professores da sala comum quanto do atendimento educacional especializado podem utilizar alguns princípios e técnicas da audiodescrição no processo de ensino e aprendizagem de estudantes público-alvo da educação especial ou que apresentem alguma necessidade ou dificuldade de aprendizagem. Os detalhes do conteúdo imagético, como os diversos ambientes, as descrições das personagens, as expressões faciais, ações que acontecem na sala de aula (como alguém entrar na sala de aula, por exemplo) são exemplos de aspectos que podem ser audiodescritos e que podem ser inseridos na fala do professor.

\section{Referências}

ALVES, F.D.; SOMMERHALDER, A. O brincar: linguagem da infância, língua infantil. Revista Motriz, Rio Claro, v.12, n. 2, p. 125-132, 2006.

BARATA, L.F.; BRANCO, A. Os distúrbios fonoarticulatórios na síndrome de down e a intervenção precoce. Revista CEFAC, v. 12, n. 1, p. 134-139, 2010. 
DOI: $10.5902 / 1984644423667$

BRASIL. Ministério das Comunicações. Lei 10.098 - de 19 de dezembro de 2000. Estabelece normas gerais e critérios básicos para a promoção da acessibilidade das pessoas portadoras de deficiência ou com mobilidade reduzida, e dá outras providências. Diário Oficial da União, Brasília, DF, 20 dez. 2000. Disponível em: <http://www.planalto.gov.br/ccivil/LEIS/L10098.htm>. Acesso em: 04 de Maio de 2015.

BRASIL. Política Nacional de Educação Especial na Perspectiva da Educação Inclusiva. Brasília: MEC/SEESP, 2008.

BRASIL. Constituição da república federativa do brasil de 1988 . Ato das Disposições Constitucionais Transitórias. Disponível em: <http://www.planalto.gov.br/ccivil_03/constituicao/constituicaocompilado.htm>. Acesso em: 24 de Maio de 2015.

CÓRIA-SABINI, M.A.; LUCENA, R.F. Jogos e brincadeiras na educação infantil. Campinas: Papirus, 2004.

COZBY, P.C. Métodos de pesquisa em ciências do comportamento. São Paulo: Editora Atlas, 2006.

FERREIRA, L. Educação, inclusão e ludicidade: uma análise histórica e filosófica. Enciclopédia Biosfera, n. 04, 2007

GARCIA, M. R; MARQUES, L. A. Brincadeiras cantadas. Porto Alegre: Kuarup, 1990.

MENDES, E. G. Inclusão marco zero: começando pelas creches. Araraquara: Junqueira \& Marins, 2010. 304 p.

MOTTA, L. M. V. M. Audiodescrição - recurso de acessibilidade para a inclusão cultural das pessoas com deficiência visual, 2008. Disponível em: <http://www.saci.org.br/index.php?modulo=akemi\&parametro=22027 . Acesso em 25 de Maio de 2015.

ROMEU FILHO, P. (Orgs.). Audiodescrição: transformando imagens em palavras. São Paulo: Secretaria dos Direitos da Pessoa com Deficiência do Estado de São Paulo, 2010.

OLIVEIRA, I. A. Política de educação inclusiva nas escolas: trajetória de conflitos. In: JESUS, D. M.; BAPTISTA, C. R.; BARRETO, M. A. S. C.; VICTOR, S. L. (Orgs.). Inclusão Práticas Pedagógicas e Trajetórias de Pesquisa. Porto Alegre: Editora Mediação, 2007. p. $32-40$.

PIAGET, J. Psicologia e Pedagogia. Rio de Janeiro: Forense Universitária, 1976.

PIAGET, J. A formação do símbolo na criança: imitação, jogo e sonho, imagem e representação. 3ª ed. Rio de Janeiro: Zahar Editores, 1978.

ROCHA, C. F. O espaço escolar em revista. In: COSTA, M. V. (Org.). Estudos culturais em Educação. Porto Alegre: Ed. UFRGS, 2000. p. 117-142. 
VYGOTSKY, L.S. A formação social da mente: o desenvolvimento dos processos psicológicos superiores. 5 ed. São Paulo: Martins Fontes, 1994.

WERNECK, C. Muito prazer, eu existo. Rio de Janeiro: WVA; 1993.

\section{Correspondência}

Tássia Lopes de Azevedo - Universidade Federal de São Carlos (UFSCar). Rodovia Washington Luís, km 235, CEP: 13565-905, São Carlos, São Paulo, Brasil.

Th is work is licensed under a Creative Commons Attribution-NonCommercial 4.0 International (CC BY-NC 4.0) 